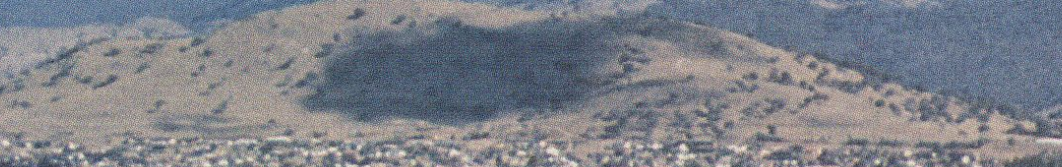

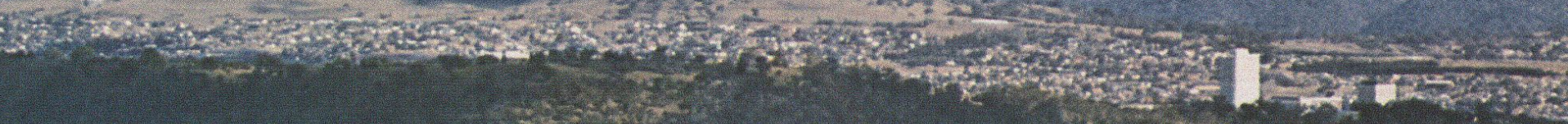

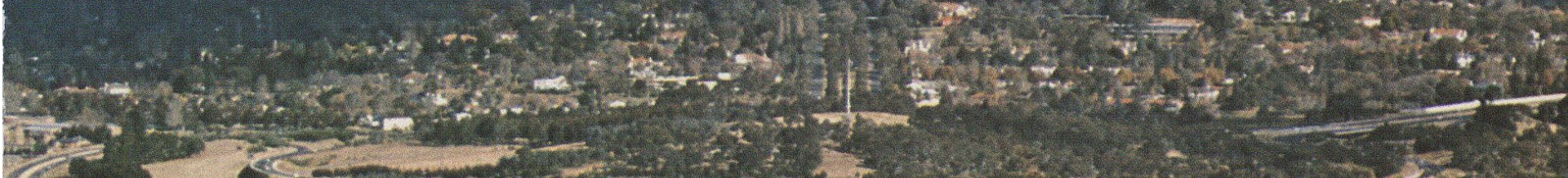

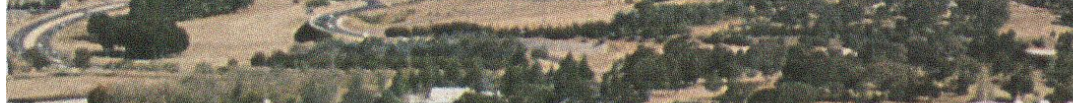

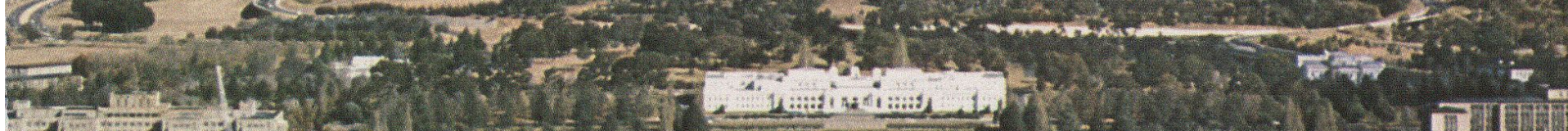

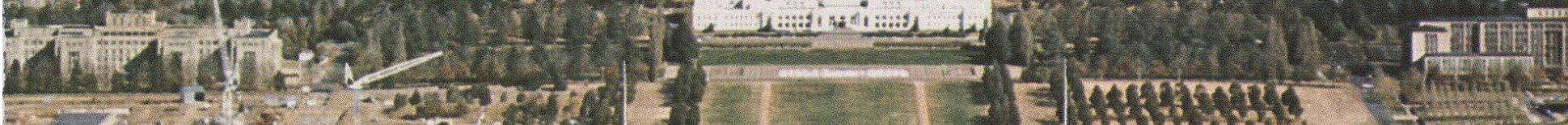

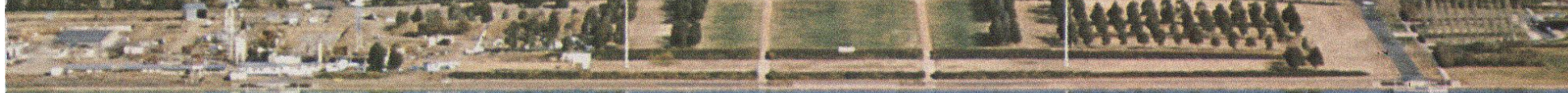

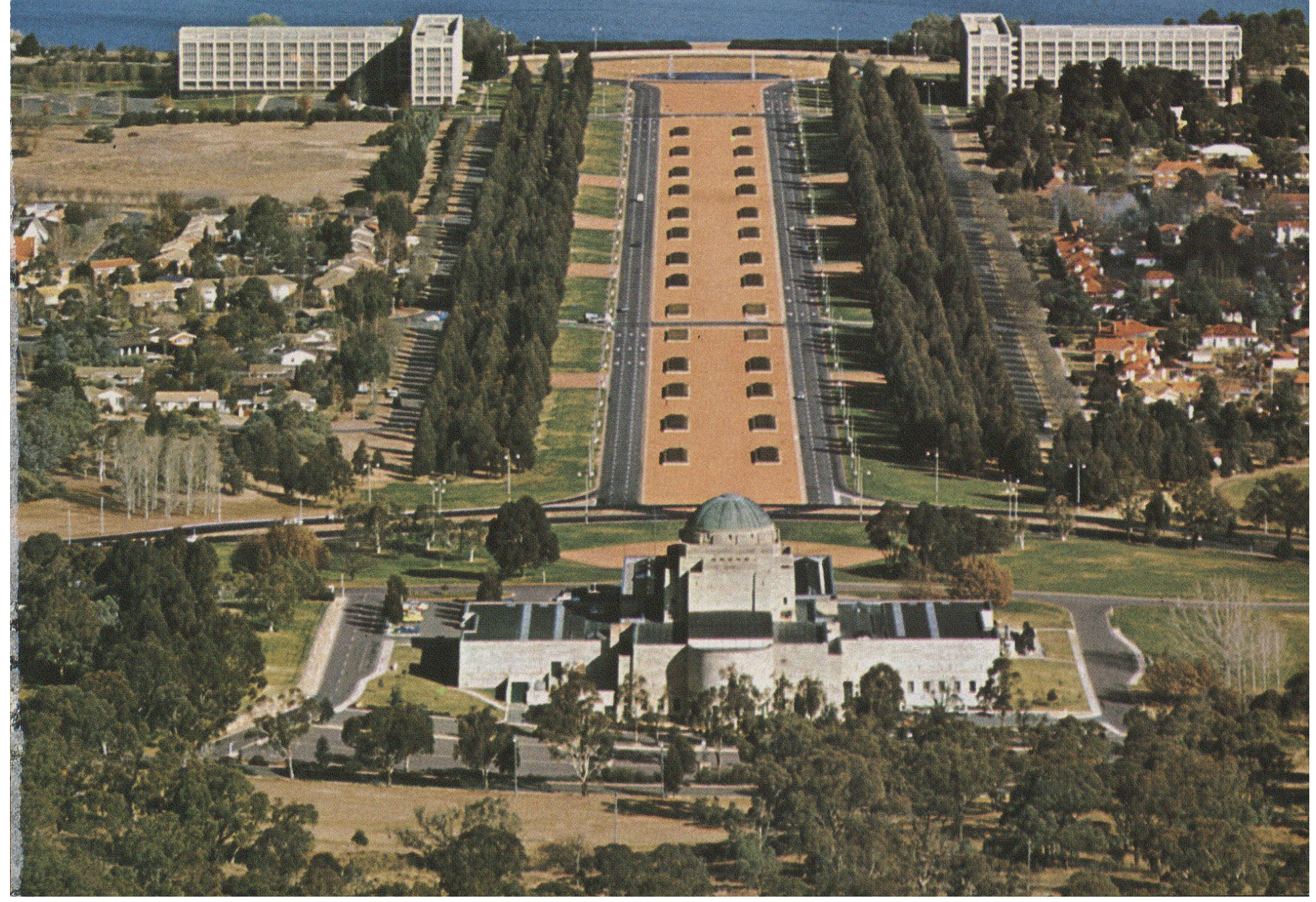




\section{Canberra, eine total geplante Stadt}

\begin{abstract}
"Ein langweiliges Dorf, eine verlorene Stadt, die einzige Hauptstadt der Welt, wo die Beamten auf dem Heimweg vom Dienst Pilze suchen und von ihrem Balkon aus Kaninchen schiessen können". Mit diesen abschätzigen und spöttischen Worten schildert Bengt Danielsson, der 1955 Australien bereist hatte, in seinem Buch "Bumerang" die australische Hauptstadt. Wenn auch diese Aeusserung als subjektiv bezeichnet werden muss, und obschon sich seither vieles geändert hat, wird Canberra auch heute noch von vielen Besuchern - nicht zuletzt auch von Australiern als eine zu künstliche und als unpersönliche Stadt bezeichnet. Canberra ist nicht nur ein Beispiel einer total geplanten Siedlung des
\end{abstract} 20. Jahrhunderts, es ist auch das Ergebnis langjähriger Zwistigkeiten zwischen Sydney und Melbourne, denn jede dieser beiden grössten Städte Australiens wollte Hauptstadt werden. Schliesslich verzichteten sie, und man einigte sich 1901, im Geburtsjahr des Australischen Bundesstaates, eine neue Hauptstadt zu gründen. Nach langem Suchen und nach vielen Konferenzen wählte man als Standort eine leicht hügelige Weidelandschaft mit Eukalyptusbeständen auf halbem Weg zwischen Sydney und Melbourne. Die rund $600 \mathrm{~m} . \mathrm{u} . M$. liegende Landschaft wird vom Molonglo durchflossen und im $W$ und $E$ von Bergen überragt. Das Klima dieses Gebietes, das etwa $125 \mathrm{~km}$ von der südlichen Westküste entfernt liegt, ist für australische Verhältnisse angenehm und wechselhaft. Die Jahresniederschlagsmenge beträgt $870 \mathrm{~mm}$, steigt aber an den benachbarten Bergen bis auf $1520 \mathrm{~mm}$ an. Der Frühling (September - November) ist gekennzeichnet durch rasche Temperaturschwankungen und häufig auftretende kühle Winde. Die Sommer sind selten extrem heiss, obschon hin und wieder Tagestemperaturen von $35^{\circ}$ gemessen werden. Am ausgeglichensten ist das Herbstklima (März-Mai), Während im Winter (Juni - August) angenehm milde bis warme Tage mit Frostnächten abwechseln. Nachdem man sich 1908 endgültig für dieses Gebiet als Standort für die neue Kapitale entschieden hatte, wurde 1911 das $2359 \mathrm{~km} 2$ grosse Australien Capital Territory geschaffen, das unmittelbar dem Australischen Bund unterstellt ist und demnach einen ähnlichen politischen Status besitzt wie der Columbia District in den USA. In der Folge wurde ein internationaler Wett bewerb veranstaltet, den der amerikanische Architekt W. Burley Griffin mit einem äusserst grosszügigen Projekt gewann. 1913 begann man mit dem Bau. Nach wiederholten Unterbrüchen der Arbeiten zufolge des Ersten Weltkrieges konnte 1927 Canberra offiziell als Regierungssitz und Hauptstadt erklärt werden. Die gesamte Stadtanlage hat für uns Europäer phantastische Züge. Wir können uns kaum vorstellen, dass man für eine Stadt so viel Platz zur Verfügung haben und so weite Grünflächen anlegen kann.

Den Mittelpunkt des Stadtgrundrisses bilden zwei niedrige Huigel, von denen radiale Strassenachsen ausstrahlen und um die konzentrische Strassenkreise angeordnet sind. Das Regierungsviertel mit repräsentativen Bauten, das Diplomatenviertel mit verschiedenen Gebäuden z.T. im jeweiligen nationalen Stil, die ausgedehnten Anlagen der australischen Nationaluniversität mit zahlreichen Institutsbauten, Wohngebiete, Geschäftsquartiere mit Einkaufszentren und immer wieder weite Parkanlagen wurden grosszügig in die Landschaft hineinkomponiert und verleihen Canberra den Charakter einer Gartenstadt. 1964 wurde der Molonglo zu einem 7 km2 grossen See, dem Lake Burley Griffin gestaut, der die Stadt in einen nördlichen und südlichen Teil gliedert und ihr das typische Gepräge gibt. Mitten aus dem See schleudert ein Springbrunnen täglich zwischen 14 und 15 Uhr sein Wasser in eine Maximalhöhe von $140 \mathrm{~m}$ empor.

Besonders auffallende Bauten im Gesamtbild der Stadt sind einige Staatsgebäude, wie z.B. das weissleuchtende Parlament, das Kriegerehrenmal, die Nationalbibliothek, die Münstätte sowie verschiedene Verwaltungs-, Geschäfts- und HotelHochhäuser. Wohnblocks sind selten, die Bewohner lieben es, in Cottages zu wohnen. Als bevorzugtes Siedlungsgebiet für diese Einfamilienhäuser gelten die Vororte an den Abhängen des Black Mountain im $W$ und des Mt. Ainslie im $E$. Es gibt diese Cottages in allen möglichen Ausführungen, vom luxuriösen Landhaus bis zum bescheidenen Häuschen aus vorfabrizierten Elementen. Aber alle sehen neu und modern aus, mit weissen Stein- oder bunten Backsteinmauern. Und jedes steht in einem sorgfältig und liebevoll gepflegten Park oder Garten mit englischem Rasen, einheimischen und exotischen Blumen, Sträuchern und Bäumen.

Bis zum Ende des Zweiten Weltkrieges erfolgte die Entwicklung von Canberra nur zögernd und - blieb hinter den Erwartungen der Behörden und Prof.Dr.W.Nigg, Loorenrain 7, 8053 Zürich 
der Oeffentlichkeit zurück. Die Nachkriegszeit brachte dann endlich den ersehnten Aufschwung. Die Bevölkerungszahl nahm zufolge der starken Zuwanderung ununterbrochen zu: 1947 17'000, 1954 30'000, $196692^{\prime} 000$ und 1973 178'000 Einwohner. Die Planer sehen bis 1985 eine Zunahme auf 250'000 vor. Die Baulücken im Zentrum sind beinahe ausgefüllt. Im Geschäftsviertel entstehen neue Hochhäuser und die Siedlung dehnt sich immer mehr aus - aber der Charakter der Gartenstadt wird gewahrt. Canberra ist eine typische Beamtenstadt. 35\% der Erwerbstätigen sind in der Verwaltung, $12 \%$ im Bau- und Transportgewerbe, $12 \%$ im Handel und $8 \%$ im diplomatischen, im Schul- und Kirchendienst beschäftigt.

Die weitere Planung von Canberra liegt in den Händen einer besonderen Kommission und stellt sehr schwierige Probleme, vor allem hinsichtlich des Verkehrs, denn die Distanzen zwischen den weitzerstreuten Siedlungsgebieten werden immer grösser. Ohne eigenes Auto ist das Leben in dieser Stadt kaum denkbar! Aber auch in soziologischer Hinsicht haben die Planer heikle Aufgaben zu lösen: In den Bewohnern, die sich entwurzelt fühlen, soll ein Heimatgefühl geweckt werden. Es gilt auch, die verschiedenartigen Berufsgruppen zusammenzuführen - dies ist bei der starken Dezentralisation der Wohngebiete keine leichte Aufgabe. Erst die nächste, vielleicht sogar erst die übernächste Generation der Einwohner von Canberra wird es erleben, ob die geplante Stadt auch in gesellschaftlicher Hinsicht einen selbständigen Charakter und eine eigene Tradition besitzt.

\section{Literatur}

King, H.W.H.: The Canberra - Queanbeyan Symbiosis. A Study of Urban Mutualism, in Geogr. Rev. 1954

Linge, G.J.R.:The future work force of Canberra. A report for the National Cap. Development. Comm., Canberra 1960

Reiner, E. Canberra; in Geogr. Rundschau 1961 Reiner $E$. und Löffler E.: Australien (S. 189 ff.), Bern 1977.

\section{Legende zum Bild}

Luftbild von Canberra: Im Vordergrund das Kriegerehrenmal (mit Kuppel), anschliessend die Anzac Parade; in der Mitte der Lake Burley Griffin, dahinter das weissleuchtende Parlamentsgebäude. An den Abhängen im Hintergrund die weitläufigen Wohnsiedlungen. 